\title{
Adamantinomatous Craniopharyngioma
}

National Cancer Institute

\section{Source}

National Cancer Institute. Adamantinomatous Craniopharyngioma. NCI Thesaurus. Code C4726.

A craniopharyngioma consisting of broad strands, cords and bridges of a multistratified squamous epithelium with peripheral palisading of nuclei. Diagnostic features include nodules of compact 'wet' keratin and dystrophic calcification. (Adapted from WHO) 